\title{
Effects of Fungi-Mediated Solid-State Fermentation on Phenolic Contents and Antioxidant Activity of Brown and White Teff (Eragrostis tef (Zucc.) Trotter) Grains
}

\author{
Yoseph Asmelash Gebru and Desta Berhe Sbhatu (iD \\ Department of Biological and Chemical Engineering, Mekelle Institute of Technology, Mekelle University, P. O. Box 1632, Tigrai, \\ Mekelle, Ethiopia \\ Correspondence should be addressed to Desta Berhe Sbhatu; desta.sbhatu@mu.edu.et
}

Received 19 May 2020; Revised 13 August 2020; Accepted 21 August 2020; Published 1 September 2020

Academic Editor: Mrcio Carocho

Copyright (c) 2020 Yoseph Asmelash Gebru and Desta Berhe Sbhatu. This is an open access article distributed under the Creative Commons Attribution License, which permits unrestricted use, distribution, and reproduction in any medium, provided the original work is properly cited.

\begin{abstract}
Teff (Eragrostis tef (Zucc.) Trotter) is a tropical cereal used in preparing a staple food in Ethiopia and Eritrea called injera. Phenolic compounds are available in soluble and bound forms in cereals like teff. Therefore, their bioaccessibility depends on their release from the food matrix. Different food processing methods including fermentation have been applied since ancient times to aid bioaccessibility and improve the properties of food products. This study aimed at investigating changes in phenolic profiles and antioxidant activities of white and brown teff grains during mushroom-mediated solid-state fermentation. Fermentation with mushroom considerably increased total phenol contents of the soluble phenol fraction with Ganoderma lucidum showing relatively higher increase than Pleurotus ostreatus. Bound fraction of teff phenol did not show noticeable changes after fermentation with the two mushroom strains. Such changes are suggested to be attributed to activities of fungal enzymes such as amylases, xylanases, and proteases that induce structural breakdown of grain components including cell walls leading to the liberation or synthesis of a variety of phenolic compounds. On the other hand, total flavonoid content of teff significantly decreased after fermentation by both strains. This is also believed to be caused by the action of fungal polyphenol oxidases that catalyze the oxidation of a variety of phenolic compounds including flavonoids to o-quinones.
\end{abstract}

\section{Introduction}

Obesity, cancer, diabetes, and allergies are nowadays becoming critical global health concerns. These chronic diseases are mostly caused by increased intake of refined carbohydrates and high calorie foods [1,2]. Cereals and pseudocereals are being considered as healthy choices due to their preventive effects against these chronic diseases. Though the nutrient compositions of these food sources vary depending on species and varieties, all provide adequate amounts of energy, proteins, vitamins, and minerals [3]. Whole grain-based foods also contain a variety of compounds with functional properties that can neutralize physiological oxidative stress in the human body [4]. Moreover, some cereal grains were found to be rich in phenolic acids, flavonoids, and saponins [1]. These bioactive compounds were proven to have antioxidant properties through radical scavenging and metal chelation [5].

Teff (Eragrostis tef (Zucc.) Trotter) is a tropical cereal. It is originated and diversified in Ethiopia, accounting for $21 \%$ of gross cereal production [6]. In Ethiopia and Eritrea, teff is primarily used to make a fermented soft pancake, locally called injera [7]. It is also served as porridge and flat bread. Outside Ethiopia and Eritrea, teff grain flour, in combination with other flours, is used to make white and brown bread, gluten-free "sprits" (Dutch shortcake cookie), gluten-free (sponge) cake, gluten-free kanos (Dutch almond fingers), and Dutch almond tartlets and pancakes [8]. As the grain is milled into whole flour before baking, it can be used as important source of bioactive compounds. Recently, it is becoming an emerging food trend and is predicted to be the next super food [9]. This is due to its gluten-free 
characteristic and its high level of essential amino acids (EAA), high mineral content, low glycemic index (GI), high crude fiber content, longer shelf life, and slow staling of its bread products as compared to wheat, sorghum, rice, barley, and maize $[10,11]$. It was also recently proved to be relatively richer in a variety of phenolic compounds compared to other common grains [6]. One recent study on teff phenolics identified 32 compounds in both the white and brown grains. Whereas the white grain variety has exclusively apigenin derivatives, the brown one has mainly luteolin derivatives [12].

Phenolic compounds are available in soluble and bound forms in teff and other cereals like wheat. Hence, the bioaccessibility of the compounds depends on their release from the food matrix. Different food processing methods including fermentation have been applied since ancient times to aid bioaccessibility and improve the properties of food products. It was long ago established that microbial fermentation changes the compositions of food products $[13,14]$. Solid-state fermentation using fungi has been applied to enhance the production of phenolic compounds and improve the antioxidant capacity of plant materials such as rice, bean, cranberry pomace, brown rice, oat, and maize; therefore fermented cereals are suitable for making of different functional ingredients [15-17]. Significant biochemical transformations take place in teff bioactive compounds during fermentation resulting changes in their compositions that, in turn, affecting the product property and bioactivity. Changes in the phenolic profiles of teff due to fermentation are important in improving the tastes of its food products and predicting its potential effects in preventing chronic diseases. The present study aimed to investigate the changes in phenolic contents and antioxidant activities of white and brown teff grain during mushroom-mediated solid-state fermentation. It evaluated changes in total phenolic content, total flavonoid content, and FRAP activities after six days of fermentation.

\section{Materials and Methods}

2.1. Chemicals and Reagents. Gallic acid, quercetin, Folin-Ciocalteu reagent, 2,20-azino-bis-(3-ethylbenzothiazoline-6-sulfonic acid), and 6-hydroxy-2,5,7,8-tetramethylchromane-2-carboxylic acid (Trolox) were purchased from SigmaAldrich (St. Louis, MO, USA). HPLC grade methanol, acetonitrile, and deionized water were purchased from J.T. Baker Co. (Phillipsburg, NJ, USA). All the other reagents were of analytical grade.

2.2. Plant Materials and Fungal Strains. Grains of white and brown teff (Eragrostis tef (Zucc.) Trotter) and two fungal strains of Ganoderma lucidum (KACC 42231) and Pleurotus ostreatus (KACC 42738) were used in this study. The fungal strains were used for solid-state fermentation of teff grain. The white and brown grain samples were obtained from local markets in Addis Ababa and Mekelle cities of Ethiopia, respectively, and were brought to South Korea with proper handling. The fungal strains were acquired through donation from the Korean Agricultural Culture Collection (KACC) of the Rural Development Administration (Wanju, Jeonbuk, Republic of Korea). Both strains, which are generally recognized as safe (GRAS), were cultivated on high-quality germinated malt extract media and maintained on potato dextrose agar (Becton, Dickinson and Company, Sparks, MD, USA) until use.

\subsection{Solid-State Fermentation of Teff Grain by Mushroom} Mycelium. Each fungal strain was initially preincubated onto potato dextrose agar. Then, it was used to inoculate a germinated malt medium $\left(13^{\circ} \mathrm{Brix}\right)$ in $150 \mathrm{~mL}$ Erlenmeyer flask prepared by saccharification of malt powder at $65^{\circ} \mathrm{C}$ with seven-fold tap water (w/v) for $16 \mathrm{hrs}$ and sterilization at $121^{\circ} \mathrm{C}$ for $15 \mathrm{~min}$. The culture was incubated for seven days at $27^{\circ} \mathrm{C}$ under shaking $(120 \mathrm{rpm})$ using an orbital shaker (model SK-600, Jeiotech Co., Ltd., Daejon, Korea). Solidstate fermentation experiment was carried out using $30 \mathrm{~g}$ of teff grain samples in $250 \mathrm{~mL}$ Erlenmeyer flask by adjusting the moisture content to about $65 \%$ by adding required volume of tap water. After that, the content was inoculated with $1 \%$ sterile fungal liquid culture. Noninoculated teff grain sample was used as matched control and each sample was incubated for six days at $27^{\circ} \mathrm{C}$ under shaking (120 rpm) to ferment. Finally, each sample was freeze-dried, ground with blender, sieved through a $1 \mathrm{~mm}$ mesh, and stored at $4^{\circ} \mathrm{C}$.

2.4. Extraction of Soluble Phenolic Compounds. Extraction of soluble phenolic compounds was carried out according to the method described by Shumoy and Raes [6] with some modifications. One (1) gram teff grain was extracted three times with $80 \%$ aqueous methanol at $1: 5$ grain/solvent ratio by shaking at $200 \mathrm{rpm}$ for $1 \mathrm{hr}$ followed by $30 \mathrm{~min}$ of sonication (Ultrasonicator, Hwa Shin Instrument Co., Seoul, Korea) at room temperature (RT). Then, the extraction mixture was centrifuged at 4,500 rpm (VS-550, Vision Scientific, Daejeon, South Korea) for $15 \mathrm{~min}$, and all supernatants from the three extractions were combined and transferred to new tubes. Finally, the extracts were filtered through $0.2 \mu \mathrm{m}$ membrane filters (Roshi Kaisha, Tokyo, Japan) and stored in refrigerator at $-20^{\circ} \mathrm{C}$ until use.

2.5. Extraction of Bound Phenolic Compounds. Extraction of bound phenolic compounds was conducted as per the method described by Abdel-Aal et al. [18] as follows. The residue left after the removal of the supernatant for soluble phenolics was dried overnight at $50^{\circ} \mathrm{C}$ incubator. One (1) gram dried residue was hydrolyzed by dissolving in $30 \mathrm{~mL}$ of $2 \mathrm{M} \mathrm{NaOH}$ and shaking in $60^{\circ} \mathrm{C}$ water bath (Namyangju, Gyeonggi-do, South Korea) for $30 \mathrm{~min}$ followed by $30 \mathrm{~min}$ of sonication. Then, the mixture was centrifuged at 4,500 rpm for $30 \mathrm{~min}$, and the supernatant was transferred to a new tube. The $\mathrm{pH}$ of the supernatant was adjusted to 1.0-3.0 with drops $6 \mathrm{~N} \mathrm{HCl}$ and defatted with $20 \mathrm{~mL}$ hexane twice while shaking for $20 \mathrm{~min}$ at RT. After removing the hexane layer by a pulse centrifugation, the supernatant was extracted twice 
with ethyl acetate (first with $30 \mathrm{~mL}$ and second with $20 \mathrm{~mL}$ ) by shaking for $20 \mathrm{~min}$ at RT. After that, the extraction mixture was centrifuged at $4,500 \mathrm{rpm}$ for $10 \mathrm{~min}$ and the ethyl acetate phase was transferred to a new tube as a bound phenolics extract. Finally, the extract was concentrated by rotary evaporation to dryness, dissolved in $80 \%$ methanol, and stored in the refrigerator at $-20^{\circ} \mathrm{C}$ until further analysis.

\subsection{Determination of Total Phenol and Total Flavonoid.} Total phenolic content (TPC) of samples was determined as per the method described by Chandra et al. [19] with some modifications. A $200 \mu \mathrm{L}$ methanol extract was mixed with $1.0 \mathrm{~mL}$ of $1 \mathrm{~N} \mathrm{NaCO}_{3}$, vortexed briefly and incubated for $2 \mathrm{~min}$ at RT. Then, $800 \mu \mathrm{L}$ Folin-Ciocalteu phenol reagent was added, and the mixture was vortexed for $10 \mathrm{sec}$. The content was incubated for $30 \mathrm{~min}$ at RT in dark condition and its absorbance was read at $720 \mathrm{~nm}$ using UV-visible spectrophotometer (Biochrom-Libra S22, Cambridge, UK) against a blank ( $80 \%$ methanol). The TPC was calculated based on a calibration curve of gallic acid. Results were expressed as mg of gallic acid equivalent per $100 \mathrm{~g}$ of the grain (mg GAE/100 g dw).

Total flavonoid content (TFC) was determined according to the method described by Zhishen et al. [20] with slight modifications. A $75 \mu \mathrm{L}$ of $5 \%$ sodium nitrite solution was added into $250 \mu \mathrm{L} \mathrm{MeOH}$ extract of each sample and vortexed briefly. After 5 min of incubation at RT, 10\% aluminum chloride was added and the mixture was vortexed. Then, the reaction mixture was incubated for $6 \mathrm{~min}$ at RT and $500 \mu \mathrm{L}$ of $1 \mathrm{~N} \mathrm{NaOH}$ was added. Finally, the total volume was adjusted to $1.0 \mathrm{~mL}$ by adding distilled water and absorbance was measured at $510 \mathrm{~nm}$ against a blank $(80 \%$ methanol). The TFC was calculated using a calibration curve of quercetin, and the results were expressed as mg quercetin equivalent $(\mathrm{QE})$ per $100 \mathrm{~g}$ of grain sample.

2.7. HPLC Analysis. The grain extract was first concentrated by rotary evaporation to $1.0 \mathrm{~mL}$ volume and filtered using a $0.20 \mu \mathrm{m}$ membrane (Roshi Kaisha, Tokyo, Japan). HPLC analysis was performed using an HPLC system (Waters, Milford, MA, USA) equipped with a 2690 separation module and Waters 996 DAD with a ZORBAX Eclipse XDB-C18 column $(250 \mathrm{~mm} \times 4.6 \mathrm{~mm}, 5 \mu \mathrm{m}$; Agilent Technologies, Inc., Santa Clara, CA, USA). The mobile phase consisted of $0.1 \%$ formic acid in deionized water (solvent $\mathrm{A}$ ) and $0.1 \%$ formic acid in methanol (solvent $\mathrm{B}$ ). The ratio of the mobile phase was maintained at $\mathrm{A}: \mathrm{B}$ 95:5 (0-5 min), 85:15 (5-10 $\mathrm{min}), 45: 55(10-25 \mathrm{~min})$, and $95: 10(25-40 \mathrm{~min})$ at a flow rate of $0.8 \mathrm{~mL} / \mathrm{min}$. UV-Vis absorption spectra were recorded from 200 to $400 \mathrm{~nm}$ during the HPLC analysis.

2.8. Ferric Reducing Antioxidant Power (FRAP). Ferric reducing power was determined using FRAP assay as described in Benzie and Strain [21] with some modifications. The FRAP reagent solution was prepared by mixing 10 volumes of $300 \mathrm{mM}$ acetate buffer ( $\mathrm{pH}$ 3.6) with 1 volume of $10 \mathrm{mM}$ TPTZ (2,4,6-tripyridyl-s-triazine) solution in $40 \mathrm{mM}$
$\mathrm{HCl}$ and 1 volume of $20 \mathrm{mM}$ ferric chloride solution. Then, $150 \mu \mathrm{L}$ methanol extract was added to $2,850 \mu \mathrm{L}$ FRAP reagent and the mixture was incubated at RT for $30 \mathrm{~min}$ in dark conditions. The absorbance of the samples was measured at $593 \mathrm{~nm}$. Trolox was used as a standard and the calibration curve was linear between $15-180 \mu \mathrm{M}$ Trolox. Results were expressed as $\mu$ mol Trolox equivalent per gram of dry grain weight ( $\mu \mathrm{M}$ TEAC/g dw).

2.9. Statistical Analysis. All tests were performed in triplicate and results were expressed as mean with standard deviation $($ mean $\pm S D)$. Statistical analyses were conducted with GraphPad prism 5 (GraphPad software, San Diego, CA, USA) for Windows and a one-way analysis of variance (ANOVA). Mean values of relevant data were compared using Duncan's multiple range tests at a priori fixed significance level of $p \leq 0.05$.

\section{Results and Discussion}

\subsection{Changes in Phenolic and Flavonoid Contents}

3.1.1. Phenolic Contents. The TPC results of mushroom mycelia-mediated solid-state fermentation (treatments) and mycelia-free (control) teff grain samples are shown in Figure 1 (see also Table 1). The G. lucidum (KACC 42231) strain was able to produce significantly higher soluble phenolic contents (fraction) than the P. ostreatus (KACC $42738)$ strain and the control in both teff varieties $(p \leq 0.05)$. The mean soluble phenolic contents generated by the $P$. ostreatus strain and the control in both varieties are nearly equal. But fermentation with G. lucidum in brown teff $(214.43 \pm 27.61 \mathrm{mg}$ GAE$/ 100 \mathrm{~g})$ resulted in statistically significantly higher soluble phenolic content than in white teff (126.22 $\pm 11.68 \mathrm{mg}$ GAE/100 g).

The amount of soluble phenolic compounds can increase due to fermentation because the metabolic processes of starter cultures improve the extractability of residual compounds [22]. Earlier studies also reported about the positive influence of fermentation on TPC and such influence varies with varying the fermenting microbial species [23]. It was shown previously that fermentation induces structural breakdown of grain components including breakdown of cell walls leading to the liberation or synthesis of a variety of bioactive compounds [13, 14]. Fungal enzymes that involve in such activities belong to amylases, xylanases, and proteases. For example, one study with wheat flour fermentation reported an increase in TPC due to the hydrolysis of covalent bonds between the phenolic compounds and cell wall matrices by $\beta$-glucosidase from Aspergillus awamori [24].

In the case of the bound fraction, there was no noticeable change in phenolic content of both teff grain varieties after fermentation. This finding can be explained in many ways as follows: (a) All the bound phenolic compounds in teff can be extracted with the soluble fraction so that not many bound compounds are left for microbial action. (b) The procedure aiming at extracting bound phenolics may not be effective in releasing such 


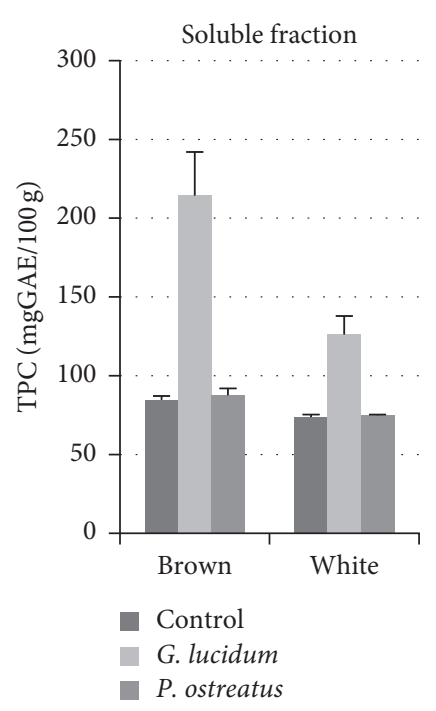

(a)

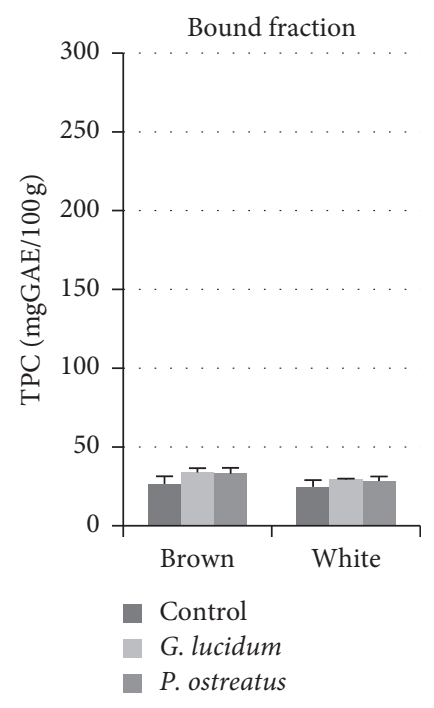

(b)

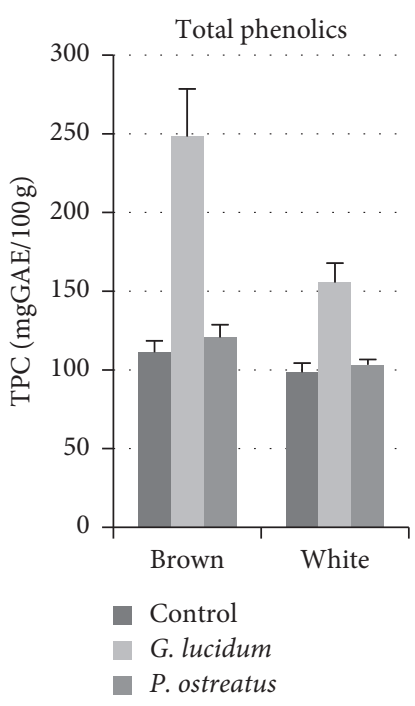

(c)

FIGURE 1: Changes in phenolic contents in teff grain samples after mushroom mycelia-based solid-state fermentation.

TABLE 1: ANOVA results of data on changes in TPC and TFC of teff due to fungal mycelia-based solid-state fermentation.

\begin{tabular}{|c|c|c|c|c|}
\hline \multirow{2}{*}{ Nature of phenolics } & \multirow{2}{*}{ Teff variety } & \multirow{2}{*}{ Source of enzyme } & \multicolumn{2}{|c|}{ Mean $( \pm$ SD) of phenolic compounds } \\
\hline & & & TPC & TFC \\
\hline \multirow{6}{*}{ Soluble } & \multirow{3}{*}{ Brown teff } & Control & $84.65 \pm 02.48^{\mathrm{ab}}$ & $252.84 \pm 08.37^{\mathrm{d}}$ \\
\hline & & G. lucidum & $214.43 \pm 27.61^{\mathrm{d}}$ & $161.93 \pm 04.51^{b}$ \\
\hline & & P. ostreatus & $83.84 \pm 00.00^{\mathrm{ab}}$ & $134.66 \pm 05.60^{\mathrm{a}}$ \\
\hline & \multirow{3}{*}{ White teff } & Control & $73.78 \pm 01.58^{\mathrm{a}}$ & $210.42 \pm 10.19^{c}$ \\
\hline & & G. lucidum & $126.22 \pm 11.68^{\mathrm{c}}$ & $173.67 \pm 12.14^{\mathrm{b}}$ \\
\hline & & P. ostreatus & $74.90 \pm 00.47^{\mathrm{a}}$ & $116.10 \pm 04.63^{\mathrm{a}}$ \\
\hline \multirow{6}{*}{ Bound } & \multirow{4}{*}{ Brown teff } & Control & $26.59 \pm 04.78^{\mathrm{a}}$ & $106.85 \pm 14.75^{\mathrm{bc}}$ \\
\hline & & G. lucidum & $33.90 \pm 02.60^{\mathrm{a}}$ & $92.23 \pm 10.76^{\mathrm{b}}$ \\
\hline & & P. ostreatus & $33.07 \pm 03.70^{\mathrm{a}}$ & $135.24 \pm 29.84^{\mathrm{d}}$ \\
\hline & & Control & $24.71 \pm 04.23^{\mathrm{a}}$ & $99.49 \pm 07.54^{\mathrm{bc}}$ \\
\hline & \multirow[t]{2}{*}{ White teff } & G. lucidum & $29.34 \pm 00.58^{\mathrm{a}}$ & $57.80 \pm 06.99^{\mathrm{a}}$ \\
\hline & & P. ostreatus & $28.39 \pm 02.86^{\mathrm{a}}$ & $64.85 \pm 12.82^{\mathrm{a}}$ \\
\hline \multirow{6}{*}{ Total } & \multirow{3}{*}{ Brown teff } & Control & $111.24 \pm 06.48^{\mathrm{bc}}$ & $359.69 \pm 07.74^{\mathrm{f}}$ \\
\hline & & G. lucidum & $248.33 \pm 26.84^{\mathrm{e}}$ & $254.16 \pm 08.68^{\mathrm{cd}}$ \\
\hline & & P. ostreatus & $116.91 \pm 03.70^{c}$ & $269.90 \pm 24.72^{\mathrm{d}}$ \\
\hline & \multirow{3}{*}{ White teff } & Control & $98.49 \pm 02.76^{\mathrm{ab}}$ & $309.91 \pm 07.28^{\mathrm{e}}$ \\
\hline & & G. lucidum & $155.56 \pm 11.13^{\mathrm{d}}$ & $231.47 \pm 14.50^{\mathrm{bc}}$ \\
\hline & & P. ostreatus & $103.29 \pm 03.22^{\mathrm{b}}$ & $180.95 \pm 13.99^{\mathrm{a}}$ \\
\hline
\end{tabular}

Values in the same column followed by different letters are statistically different $(p \leq 0.05)$.

compounds. Ethyl acetate may not be effective extraction solvent and the use of alkaline and acidic extraction solvents may be helpful. (c) The fact that only one of the fungal strains is effective in generating soluble phenols implies that the strains may not be good sources of enzymes responsible for the release of bound phenolic compounds.

3.1.2. Flavonoid Contents. The tests for TFC showed that fungal strain-free (control) fermentation of the grain samples resulted in statistically higher soluble flavonoid content in both the brown $(252.84 \pm 8.37 \mathrm{mg} \mathrm{QE} / 100 \mathrm{~g})$ and white $(210.42 \pm 10.19 \mathrm{mg} Q \mathrm{QE} / 100 \mathrm{~g})$ teff varieties compared to that of fungal strain-mediated fermentation $(p \leq 0.05)$ (Figure 2 and Table 1). This being the principal finding, the amount of soluble flavonoid content generated after $G$. lucidum-mediated grain fermentation is statistically higher than that generated after $P$. ostreatus-mediated fermentation $(p \leq 0.05)$ in both teff varieties. The low level of soluble flavonoid generated by mushroom-based fermentation is accounted to the effectiveness of polyphenol oxidases 


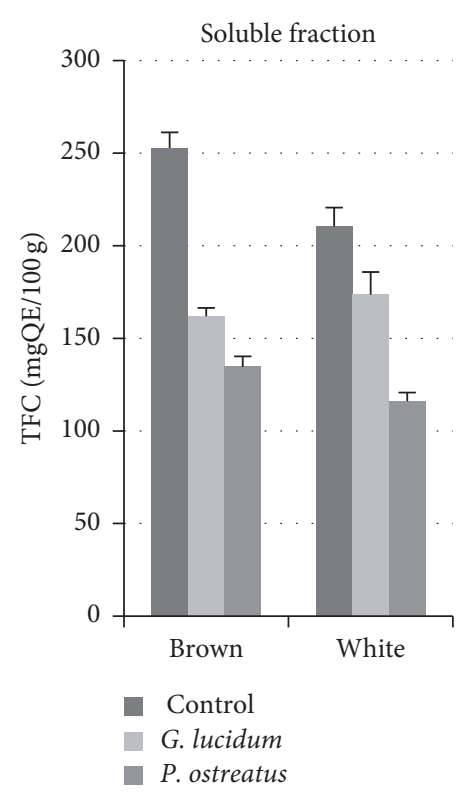

(a)

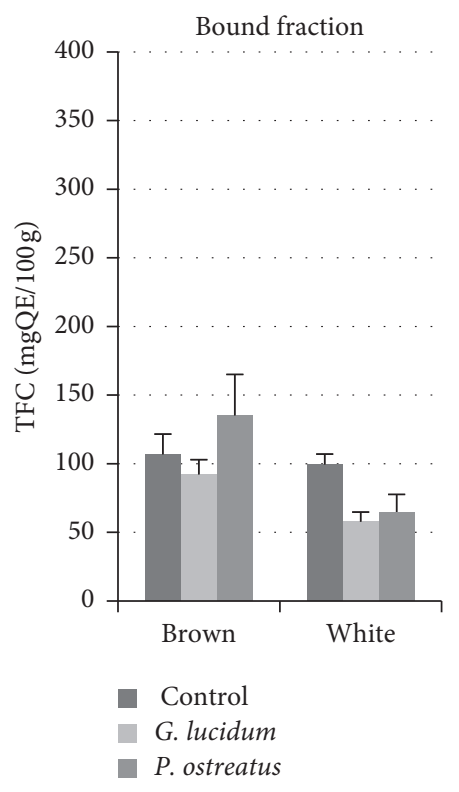

(b)

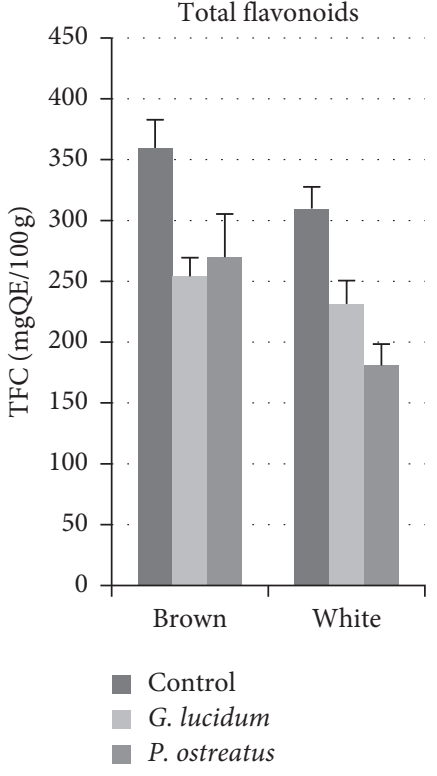

(c)

Figure 2: Changes in flavonoid contents of teff grain samples after mushroom mycelium-based solid-state fermentation.

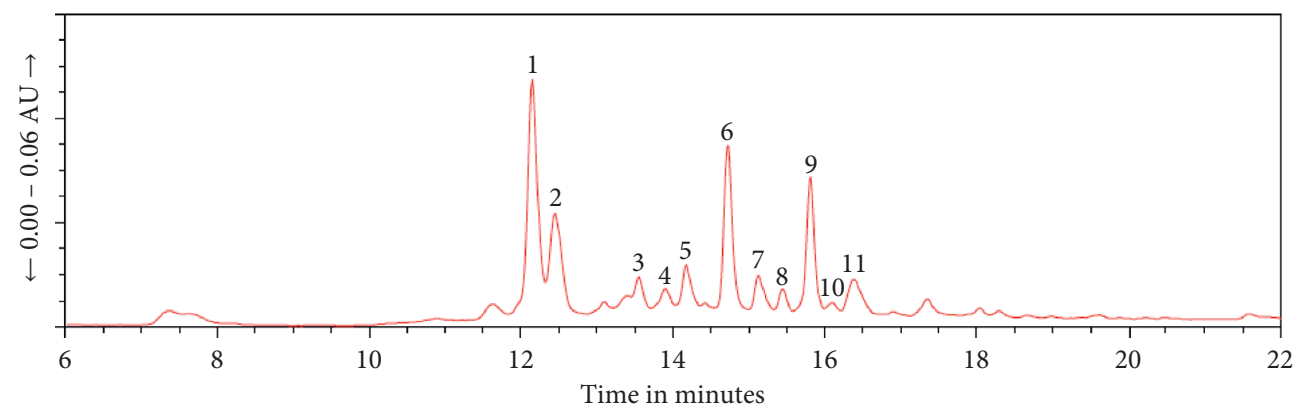

(a)

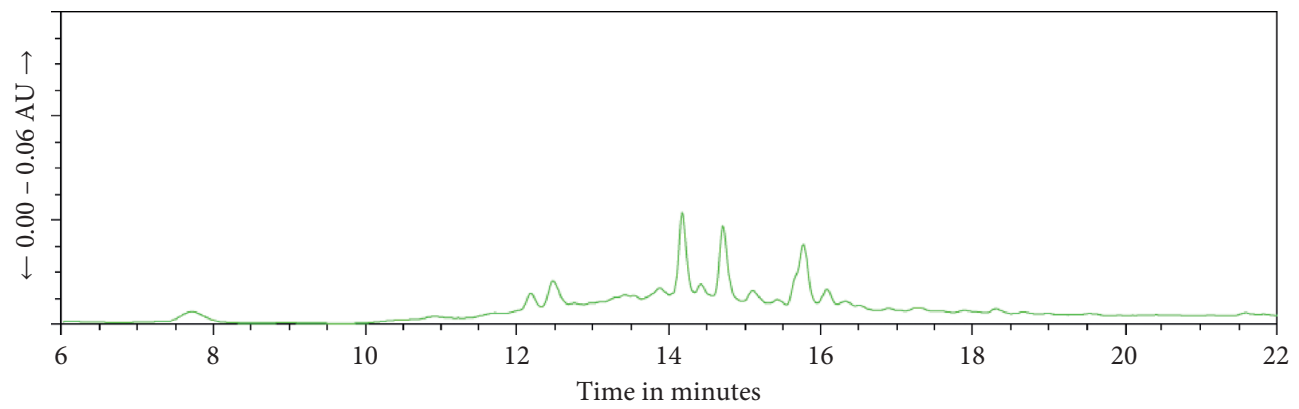

(b)

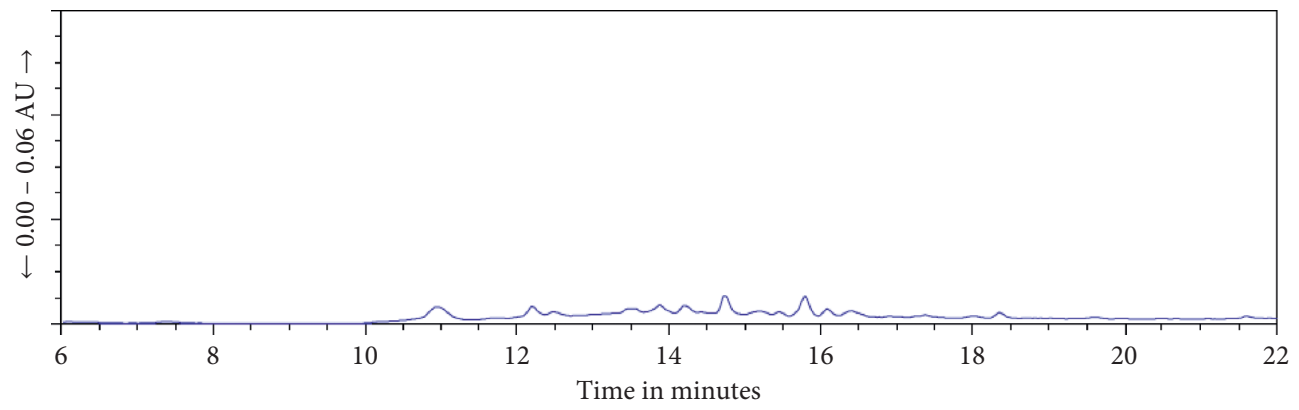

(c)

Figure 3: Changes in HPLC patterns of brown teff phenolic compounds (soluble fraction) due to mushroom mycelium-mediated solid-state fermentation. (a) Matched control (unfermented); (b) G. lucidum (KACC 42231); (c) P. ostreatus (KACC 42738). 
TABLE 2: Characterization of major compounds identified in soluble and bound fractions.

\begin{tabular}{|c|c|c|c|c|c|c|c|c|}
\hline \multirow{2}{*}{$\begin{array}{l}\text { Peak } \\
\text { no. }\end{array}$} & \multirow{2}{*}{$\begin{array}{c}t_{\mathrm{R}} \\
(\mathrm{min})\end{array}$} & \multirow[b]{2}{*}{ Tentative assignment } & \multicolumn{2}{|c|}{$m / z$} & \multirow{2}{*}{$\begin{array}{l}\text { Mass } \\
\text { error } \\
(\mathrm{ppm})\end{array}$} & \multirow{2}{*}{$\begin{array}{l}\text { Molecular } \\
\text { formula }\end{array}$} & \multicolumn{2}{|c|}{ MS/MS fragment ions } \\
\hline & & & *Anion & Cation & & & Anion & Cation \\
\hline 1 & 3.67 & Kaempferol-3-gentiobioside & 609.1461 & 611.1603 & 0.00 & $\mathrm{C}_{27} \mathrm{H}_{30} \mathrm{O}_{16}$ & $\begin{array}{c}367.0614,369.0612 \\
591.1341\end{array}$ & $\begin{array}{l}329.0653, \\
353.0653, \\
299.0547\end{array}$ \\
\hline 2 & 3.73 & $\begin{array}{l}\text { Kaempferol-3-O-rutinosyl-7- } \\
\text { O- } \beta \text {-D-glucoside }\end{array}$ & 755.2043 & 757.2187 & 0.40 & $\mathrm{C}_{33} \mathrm{H}_{40} \mathrm{O}_{20}$ & $\begin{array}{c}447.0930,328.0544 \\
259.0614\end{array}$ & $\begin{array}{l}395.0705 . \\
431.0969 \\
757.2177\end{array}$ \\
\hline 3 & 3.98 & 3,8-Di-C-glucosylapigenin & 593.1512 & 595.1655 & -0.30 & $\mathrm{C}_{27} \mathrm{H}_{30} \mathrm{O}_{15}$ & $\begin{array}{c}311.0562,283,0659 \\
341.0666\end{array}$ & - \\
\hline 4 & 4.02 & $\begin{array}{l}\text { Genistein- } 7,4^{\prime} \text {-di-O- } \beta \text {-D- } \\
\text { glucoside }\end{array}$ & - & 595.1655 & -1.00 & $\mathrm{C}_{27} \mathrm{H}_{30} \mathrm{O}_{15}$ & 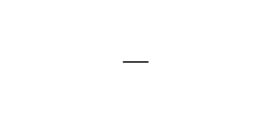 & $\begin{array}{l}283.0599, \\
313.0704, \\
379.0808\end{array}$ \\
\hline 5 & 4.04 & Grosvenorine & - & 741.2239 & 0.30 & $\mathrm{C}_{33} \mathrm{H}_{40} \mathrm{O}_{19}$ & - & $\begin{array}{c}283.0599, \\
313.0704, \\
595.1651\end{array}$ \\
\hline 6 & 4.24 & Populnin & 447.0934 & 449.1079 & 0.20 & $\mathrm{C}_{21} \mathrm{H}_{20} \mathrm{O}_{11}$ & $\begin{array}{c}327.0511,299.0552 \\
133.0295\end{array}$ & $\begin{array}{l}299.2550 \\
329.0655 \\
271.0598\end{array}$ \\
\hline 7 & 4.49 & Viscumneoside VII & - & 791.2040 & 4.50 & $\mathrm{C}_{34} \mathrm{H}_{40} \mathrm{O}_{20}$ & - & $\begin{array}{l}287.0550, \\
329.0656, \\
3921.0809\end{array}$ \\
\hline 8 & 4.51 & Genistin & 431.0982 & 433.1127 & -0.40 & $\mathrm{C}_{21} \mathrm{H}_{20} \mathrm{O}_{10}$ & $\begin{array}{c}311.0652,283.0611 \\
161.0246\end{array}$ & $\begin{array}{c}313.0734, \\
283.0599, \\
337.0708\end{array}$ \\
\hline 9 & 4.66 & Carthamin & 909.2082 & - & -1.40 & $\mathrm{C}_{43} \mathrm{H}_{42} \mathrm{O}_{22}$ & $\begin{array}{c}759.1779,327.0508 \\
357.0619\end{array}$ & - \\
\hline 10 & 4.80 & Smiglaside D & 965.2743 & - & 2.30 & $\mathrm{C}_{47} \mathrm{H}_{50} \mathrm{O}_{22}$ & $\begin{array}{c}311.0565,773.1930 \\
473 ., 1088\end{array}$ & - \\
\hline 11 & 4.85 & Sophorabioside & 577.1559 & 579.1707 & -0.20 & $\mathrm{C}_{27} \mathrm{H}_{30} \mathrm{O}_{14}$ & $\begin{array}{c}269.0455,577.1557 \\
473.1086\end{array}$ & $\begin{array}{l}271.0598 \\
433.1104 \\
153.0177\end{array}$ \\
\hline 12 & 4.98 & $\begin{array}{l}\text { Apigenin-7-O-(6"-syringyl) } \\
\text { arabinosyl-8-C-glucoside }\end{array}$ & - & 745.1981 & -0.20 & $\mathrm{C}_{26} \mathrm{H}_{28} \mathrm{O}_{14}$ & - & $\begin{array}{c}313.0735 \\
293.0605 \\
151.0419\end{array}$ \\
\hline 13 & 5.07 & $\begin{array}{l}\text { Luteolin-3-O-(6"-O-acetyl)- } \\
\beta \text {-D-glucoside }\end{array}$ & 489.1038 & 491.1183 & -0.20 & $\mathrm{C}_{23} \mathrm{H}_{23} \mathrm{O}_{11}$ & $\begin{array}{c}327.0511,431.0975 \\
268.0373\end{array}$ & $\begin{array}{l}277.0591 \\
329.0653, \\
353.0655\end{array}$ \\
\hline 14 & 5.42 & $\begin{array}{l}\text { Apigenin-7-O- } \beta \text {-D- } \\
\text { glucuronide ethyl ester }\end{array}$ & 473.1088 & 475.1232 & -0.20 & $\mathrm{C}_{23} \mathrm{H}_{22} \mathrm{O}_{11}$ & $\begin{array}{c}311.0563,283.0611 \\
413.0875\end{array}$ & $\begin{array}{l}283.0598, \\
313.0704, \\
271.0599\end{array}$ \\
\hline 15 & 5.65 & Pinnatifinoside I & 515.1192 & - & -0.60 & $\mathrm{C}_{21} \mathrm{H}_{18} \mathrm{O}_{9}$ & $\begin{array}{c}455.0978 \\
311.0563,283.0603\end{array}$ & - \\
\hline 16 & 4.48 & $5,7,3^{\prime}, 4^{\prime}$-Tetramethoxyflavone & 387.1084 & - & -0.30 & $\mathrm{C}_{19} \mathrm{H}_{18} \mathrm{O}_{6}$ & $\begin{array}{c}193.0508,134.0375 \\
343.1179\end{array}$ & - \\
\hline 17 & 4.67 & 7-Methoxycoumarin & - & 177.0543 & -1.70 & $\mathrm{C}_{10} \mathrm{H}_{8} \mathrm{O}_{3}$ & - & $\begin{array}{c}177.0543 \\
145.0218\end{array}$ \\
\hline 18 & 4.83 & $5,7,3^{\prime}, 4^{\prime}$-Tetramethoxyflavone & 387.1080 & - & -1.30 & $\mathrm{C}_{19} \mathrm{H}_{18} \mathrm{O}_{6}$ & $\begin{array}{c}134.0370,295.0607 \\
266.0585\end{array}$ & - \\
\hline 19 & 5.59 & $\begin{array}{l}\text { 6-Aldehydo-isoophio- } \\
\text { pogonone B }\end{array}$ & 385.0927 & - & -0.50 & $\mathrm{C}_{19} \mathrm{H}_{14} \mathrm{O}_{7}$ & $\begin{array}{c}281.0816,267.0653 \\
235.0756\end{array}$ & - \\
\hline 20 & 5.93 & (-) Sclerodin & - & 351.0856 & 4.80 & $\mathrm{C}_{18} \mathrm{H}_{16} \mathrm{O}_{6}$ & - & $\begin{array}{c}279.0643, \\
323.0904, \\
192.0563\end{array}$ \\
\hline
\end{tabular}

${ }^{*}$ Anion: $[\mathrm{M}-\mathrm{H}]^{-}$or $[\mathrm{M}-\mathrm{HCOO}]^{-}$; cation: $[\mathrm{M}+\mathrm{H}]^{+}$or $[\mathrm{M}+\mathrm{Na}]^{+}$.

secreted from the starter cultures. Polyphenol oxidases (EC 1.14.18.1), common enzymes in a wide range of fungal strains, catalyze the oxidation of a variety of phenolic compounds including flavonoids to o-quinones [25]. But the changing environment during fermentation might have caused flavonoid compounds to interact or bind with proteins and polysaccharides to make them less responsive to the fungal enzymes [26]. 


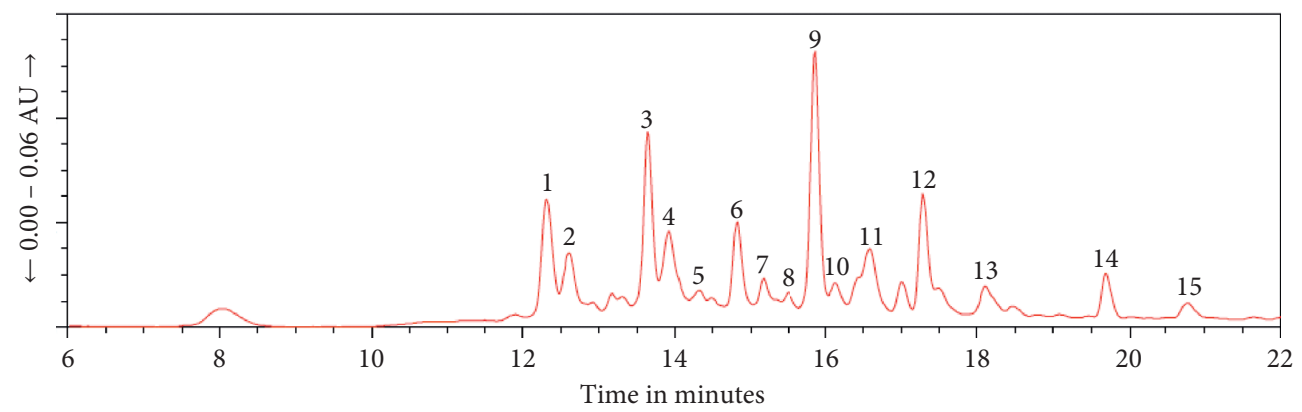

(a)

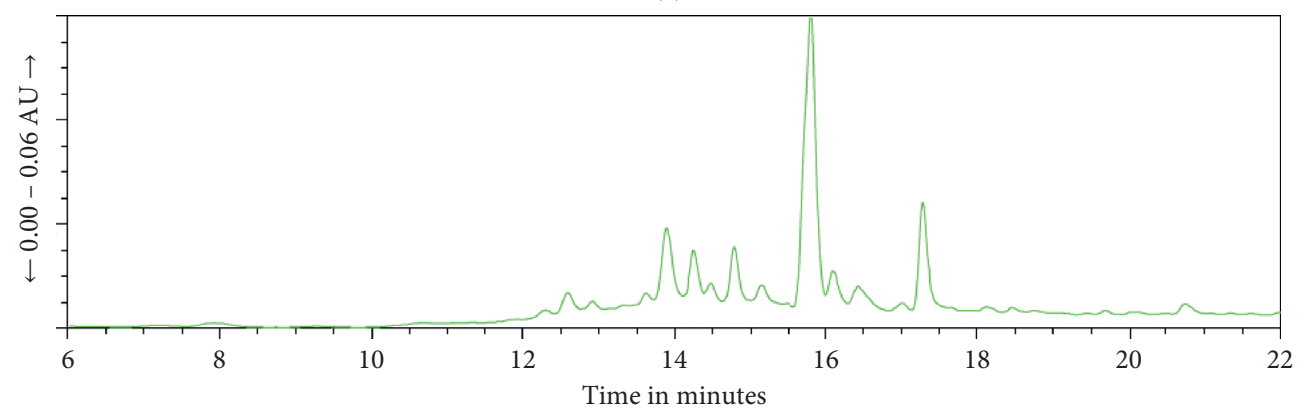

(b)

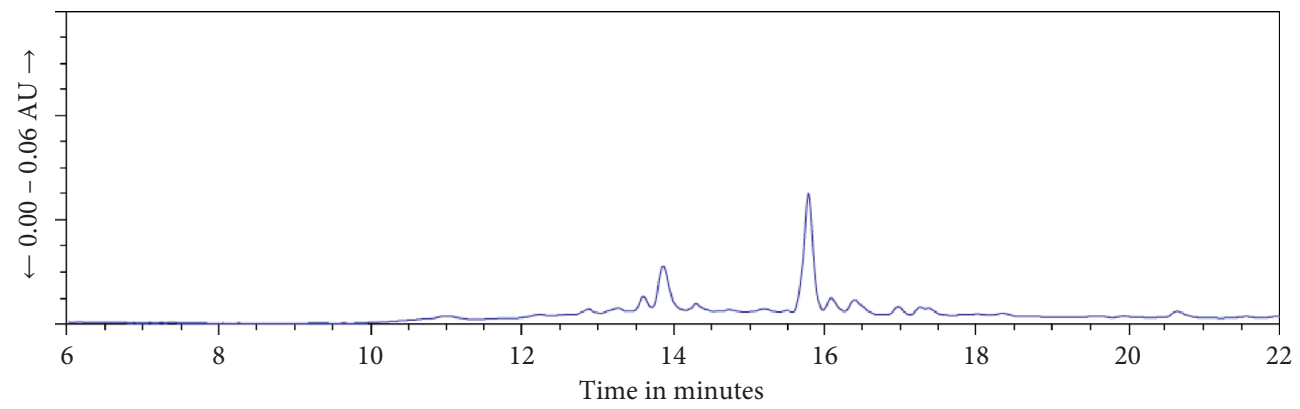

(c)

FIGURE 4: Changes in HPLC patterns of white teff phenolic compounds (soluble fraction) due to mushroom mycelium-mediated solid-state fermentation. (a) Matched control (unfermented); (b) G. lucidum (KACC 42231); (c) P. ostreatus (KACC 42738).

The release of the bound flavonoid fraction was statistically higher $(135.24 \pm 29.84 \mathrm{mg} \mathrm{QE} / 100 \mathrm{~g})$ in the $P$. ostreatus-mediated brown teff grain fermentation $(p \leq 0.05)$. However, the remaining fungi-mediated fermentation treatments produced statistically comparable amount of bound flavonoids to that of the fungi-free (control) fermentation (Figure 2, Table 1). The release of a relatively higher amount of bound flavonoids in the brown teff variety may be attributed to the presence of condensed tannins in the variety [12]. Condensed tannins, believed to give the brown teff its characteristic color, are flavonoid oligomers that are widely distributed in plants. It is evident that the two strains showed different patterns in the release of soluble and bound TPC and TFC in the fermentation of both teff varieties. Therefore, further studies that aim at elucidating these differences may be carried out using other extraction media, the stability or resistance of the phenolic and flavonoid compounds before and after solubilization, the nature and efficiency of the enzymes of the fermenting strains, and the mechanisms of change in the phenolic and flavonoid contents during fermentation.

\subsection{Changes in HPLC Chromatogram Patterns}

3.2.1. Soluble Fraction. HPLC analysis was conducted with all samples extracted from the same grain using the same conditions to examine the peak patterns of individual compounds. The peak patterns are given in Figures 3-6 and the compounds corresponding to the peaks were identified through UPLC-qTOF-MS. Their identities and characterizations are shown in Table 2-peak nos. 1 to 11 are for brown teff (Figure 3) and 1 to 15 for white teff (Figure 4). Visual inspection of the base peak chromatogram patterns of soluble phenolic fraction depicted in Figure 3 (brown teff) and Figure 4 (white teff) showed that the intensities of almost all the peaks decreased after fermentation. The effect of G. lucidum on white teff grain fermentation (Figure 3) was not as profound as that of $P$. ostreatus strain (Figure 3 ). Since the peaks predominantly correspond to flavonoids; it validates the decrease in TFC observed in the results of the TFC assay described above. Whereas all the peaks in the $P$. ostreatus fermented sample disappeared, the reductions in the G. lucidum 


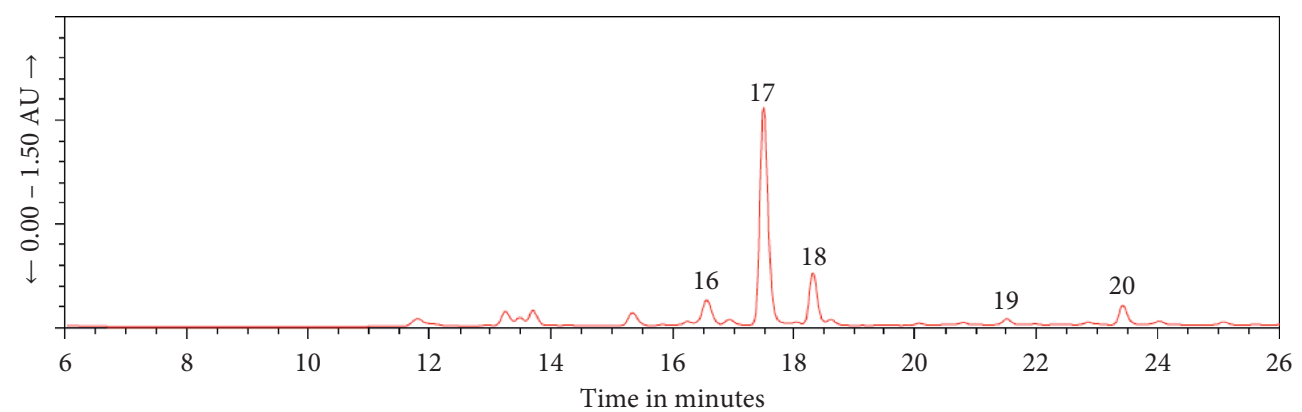

(a)

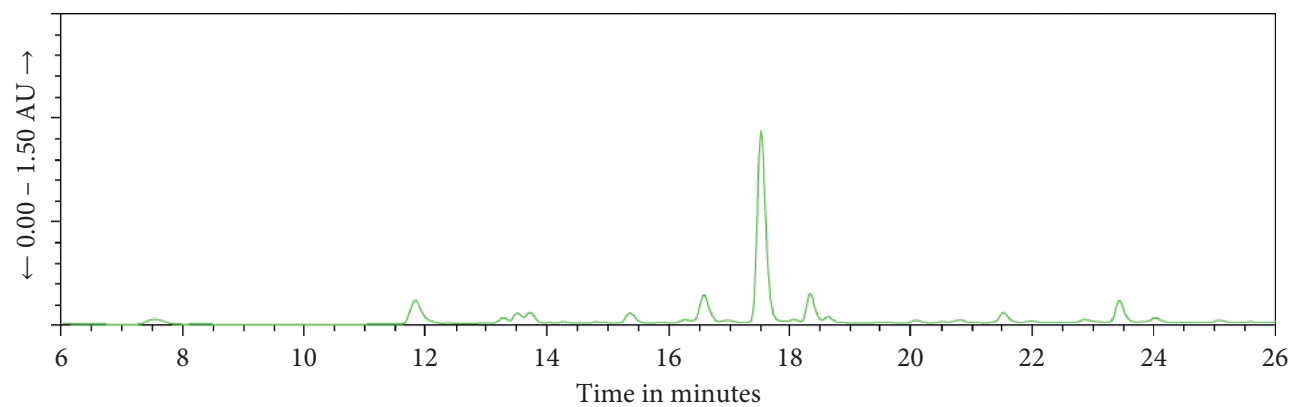

(b)

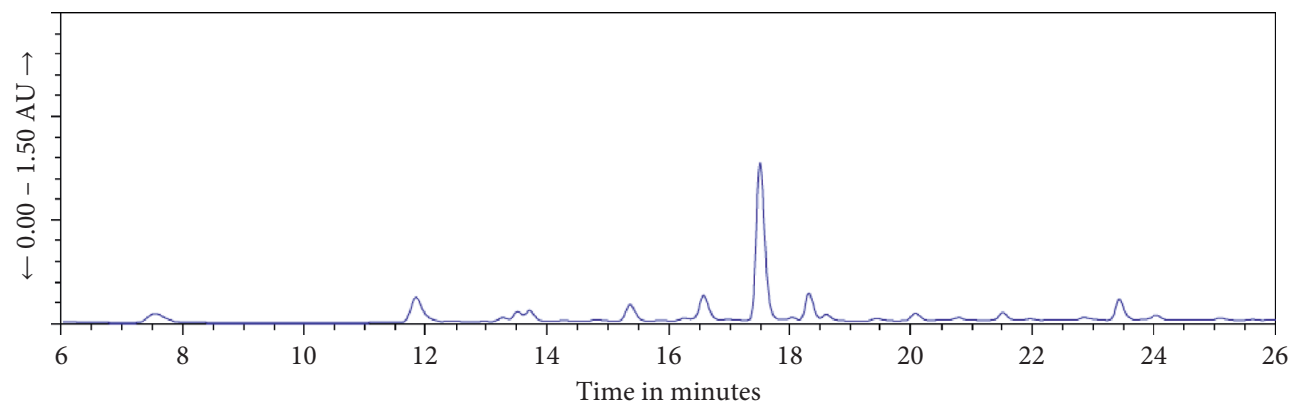

(c)

Figure 5: Changes in HPLC patterns of brown teff phenolic compounds (bound fraction) due to mushroom mycelium-mediated solid-state fermentation. (a) Matched control (unfermented); (b) G. lucidum (KACC 42231); (c) P. ostreatus (KACC 42738).

fermented sample were less profound. This is additional evidence for the less profound decrease in TFC observed due to G. lucidum-mediated teff grain fermentation as compared to the $P$. ostreatus-mediated fermentation in the TFC determination assay presented above.

The decrease in each compound could be due to the degradation or enzymatic polymerization of the released free phenolics by the fermenting fungal strain. Some recent studies reported that fungal fermentation may cause degradation and polymerization of phenolic compounds at later stages of the fermentation processes $[27,28]$. But not all peaks were decreased due to fermentation. For instance, the area of "peak 5" increased by $51 \%$ in the brown and by $46.9 \%$ in the white teff samples after fermentation with G. lucidum. Similarly, "peak 9" showed a slight increase in the G. lucidum fermented sample of white teff. These indicate that molecular transformation processes may vary between grain types. Polymeric forms of teff grain phenolic compounds, often catalyzed by fungal enzymes, are activated in response to the changes in the media composition [27-29].
3.2.2. Bound Fraction. The change in HPLC patterns of individual compounds of the bound fraction was not noticeable in both brown and white teff grains (Figures 5 and 6). Comparison of the amount of individual peaks (Table 2, peaks nos. 16 to 20) estimated as described above also did not show significant variations.

3.3. Changes in FRAP Activity. It is evident that mushroommediated solid-state fermentation of brown and white teff grains significantly decreases their antioxidant activities with one exception (Table 3). Brown teff grain sample fermented using $P$. ostreatus (KACC 42738) yielded the highest mean FRAP value of $29.49 \pm 2.22 \mu \mathrm{mol}$ of TEAC/g dw in its bound fraction $(p \leq 0.05)$. The trend in the FRAP results corroborates the results of phenolic content studies. With the exception of $G$. lucidum (KACC 42231) that resulted in increased phenolic content of the soluble fraction of the brown and white teff grain, the rest of the mushroom-mediated solid-state fermentation tests resulted in decreased total phenolic and flavonoid contents (Figures 1 and 2). 


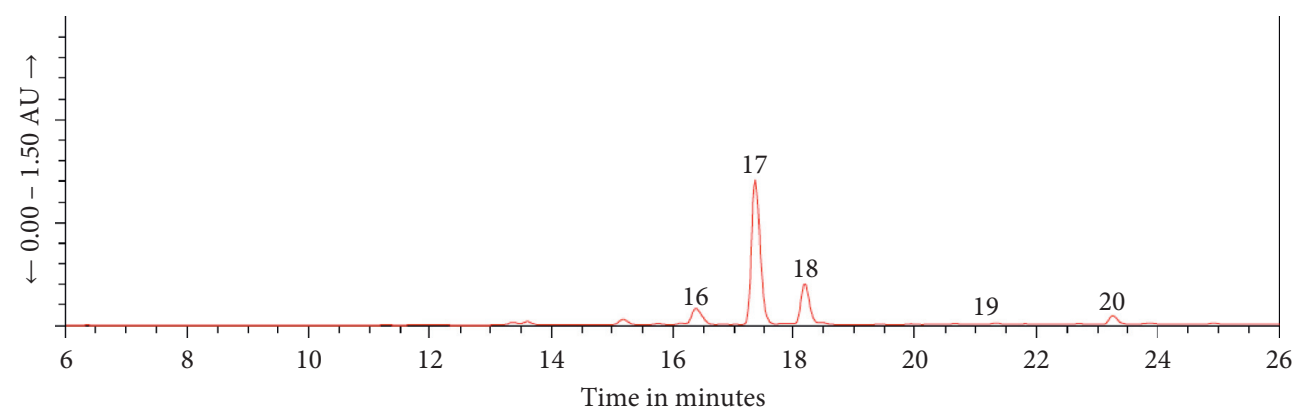

(a)

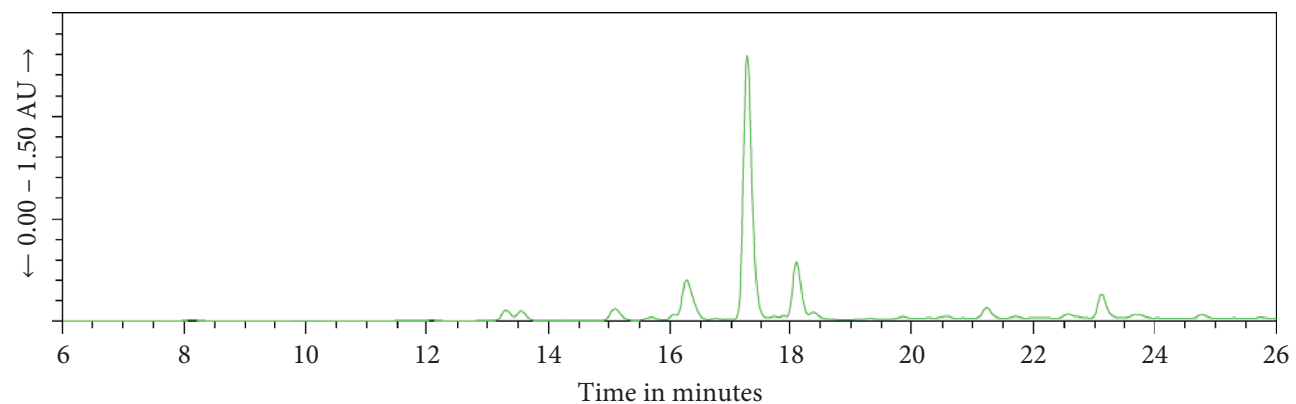

(b)

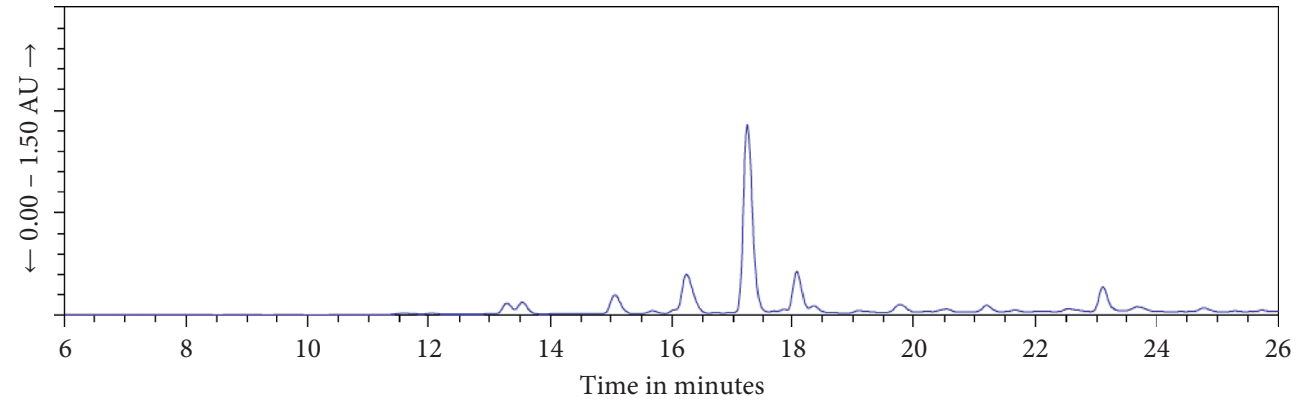

(c)

FIGURE 6: Changes in HPLC patterns of white teff phenolic compounds (bound fraction) due to mushroom mycelium-mediated solid-state fermentation. (a) Matched control (unfermented); (b) G. lucidum (KACC 42231); (c) P. ostreatus (KACC 42738).

TABLE 3: Changes in FRAP of teff grain during mushroom myceliamediated solid-state fermentation.

\begin{tabular}{lcccc}
\hline \multirow{2}{*}{$\begin{array}{l}\text { Grain } \\
\text { type }\end{array}$} & Fermentation & \multicolumn{3}{c}{ FRAP $(\mu \mathrm{mol}$ of TEAC/g dw $)$} \\
& & Soluble & Bound & Total \\
\hline \multirow{3}{*}{ Brown } & Unfermented & $12.11 \pm 0.50^{\mathrm{e}}$ & $24.36 \pm 1.64^{\mathrm{c}}$ & $36.47 \pm 2.14^{\mathrm{c}}$ \\
& G. lucidum & $7.76 \pm 0.24^{\mathrm{c}}$ & $19.66 \pm 1.28^{\mathrm{b}}$ & $27.42 \pm 1.46^{\mathrm{b}}$ \\
& P. ostreatus & $6.45 \pm 0.26^{\mathrm{b}}$ & $29.49 \pm 2.22^{\mathrm{d}}$ & $35.94 \pm 2.45^{\mathrm{c}}$ \\
\hline \multirow{4}{*}{ White } & Unfermented $^{\mathrm{c}}$ & $10.08 \pm 0.43^{\mathrm{d}}$ & $17.99 \pm 0.76^{\mathrm{b}}$ & $28.07 \pm 1.16^{\mathrm{b}}$ \\
& G. lucidum & $8.32 \pm 0.42^{\mathrm{c}}$ & $8.59 \pm 0.28^{\mathrm{a}}$ & $16.91 \pm 0.70^{\mathrm{a}}$ \\
& P. ostreatus & $5.56 \pm 0.21^{\mathrm{a}}$ & $10.85 \pm 0.46^{\mathrm{a}}$ & $16.41 \pm 0.67^{\mathrm{a}}$ \\
\hline
\end{tabular}

FRAP: ferric reducing antioxidant power; TEAC: Trolox equivalent antioxidant activity. Values in the same column followed by different letters are statistically different $(p \leq 0.05)$.

The antioxidant activities have significantly decreased in both grain types with the exception of the bound fraction of brown teff grain fermented with $P$. ostreatus that showed a slight increase (Figures 5 and 6). The trend in the FRAP result also seems to be similar to that of phenolic content determinations. While the total phenol content results showed increment after fermentation, their contribution towards antioxidant activities is negligible as the polyphenols in teff are predominantly flavonoid molecules. It can be seen from the results that TFC has significantly decreased after fermentation (Figure 2).

Generally, it can be concluded that the phenolic contents and antioxidant activities of teff diminished after fermentation. However, the present study was based on one six-day fermentation test. It is well known that fermentation time is a kinetic parameter with importance for optimal enzyme production, thereby affecting transformation and production of particular compounds. Hence, future studies on the effects of fermentation on phenolics of teff grain might be designed with different fermentation time and conditions.

\section{Concluding Remarks}

Mushroom mycelia-mediated solid-state fermentation of brown and white teff grain for six days using G. lucidum (KACC 42231) and P. ostreatus (KACC 42738) as starter cultures resulted in the decrement in the total phenolic contents and antioxidant activities. The studies aiming at 
evaluating the changes in phenolic and flavonoid contents, examining changes in the HPLC chromatogram patterns, and assessing the changes in the FRAP activities generally showed that fermentation of the teff grain using the two mushroom strains reduced their phenolic contents and antioxidant activities. But there are three exceptions that require further inquiry as follows: (a) Unlike the control and the P. ostreatus (KACC 42738) strain, G. lucidum (KACC 42231) was able to produce significantly higher soluble phenolic content in both teff varieties. (b) Fermentation with G. lucidum (KACC 42231) increased "peak 5" of the soluble phenolic fraction by 51 and $46.9 \%$ in brown and white teff grain samples, respectively. It also slightly increased "peak 9" of the soluble flavonoid fraction of white teff grain samples. (c) Fermentation of brown teff grain with P. ostreatus (KACC 42738) resulted in the highest mean FRAP value that is comparable to unfermented brown teff and significantly higher than the unfermented white teff grain. These findings imply that it is helpful to explore into the effects of the tested strains under different fermentation time and conditions.

\section{Data Availability}

The datasets used and/or analyzed during the current study are available from the corresponding author upon reasonable request.

\section{Conflicts of Interest}

The authors declare that they have no conflicts of interest.

\section{References}

[1] A. Cencic and W. Chingwaru, "The role of functional foods, nutraceuticals, and food supplements in intestinal health," Nutrients, vol. 2, no. 6, pp. 611-625, 2010.

[2] L. S. Gross, L. Li, E. S. Ford, and S. Liu, "Increased consumption of refined carbohydrates and the epidemic of type 2 diabetes in the United States: an ecologic assessment," The American Journal of Clinical Nutrition, vol. 79, no. 5, pp. 774-779, 2004.

[3] S. D. Senter, R. J. Horvat, and W. R. Forbus, "Comparative GLC-MS analysis of phenolic acids of selected tree nuts," Journal of Food Science, vol. 48, no. 3, pp. 798-799, 1983.

[4] I. Björck, E. Östman, M. Kristensen et al., "Cereal grains for nutrition and health benefits: overview of results from in vitro, animal and human studies in the HEALTHGRAIN project," Trends in Food Science \& Technology, vol. 25, no. 2, pp. 87-100, 2012.

[5] C. Liyana-Pathirana, J. Dexter, and F. Shahidi, "Antioxidant properties of wheat as affected by pearling," Journal of Agricultural and Food Chemistry, vol. 54, no. 17, pp. 6177-6184, 2006.

[6] H. Shumoy and K. Raes, "Antioxidant potentials and phenolic composition of tef varieties: an indigenous Ethiopian cereal," Cereal Chemistry Journal, vol. 93, no. 5, pp. 465-470, 2016.

[7] M. Umeta and R. M. Faulks, "The effect of fermentation on the carbohydrates in tef (Eragrostis tef)," Food Chemistry, vol. 27, no. 3, pp. 181-189, 1988.

[8] EPO (European Patent Office), "Processing of teff flour. European patent specification (EP 1646287 B1)," 2019, https://data.epo.org.
[9] A. O'connor, Is Teff the New Super Grain?, The New York Times, New York, NY, USA, 2016.

[10] W. Zhang, J. Xu, J. L. Bennetzen, and J. Messing, “Teff, an orphan cereal in the chloridoideae, provides insights into the evolution of storage proteins in grasses," Genome Biology and Evolution, vol. 8, no. 6, pp. 1712-1721, 2016.

[11] K. Baye, Teff: Nutrient Composition and Health Benefits, International Food Policy Research Institute, Washington, DC, USA, 2014.

[12] S. Ravisankar, K. Abegaz, and J. M. Awika, "Structural profile of soluble and bound phenolic compounds in teff (Eragrostis tef) reveals abundance of distinctly different flavones in white and brown varieties," Food Chemistry, vol. 263, pp. 265-274, 2018.

[13] K. Katina, A. Laitila, R. Juvonen et al., "Bran fermentation as a means to enhance technological properties and bioactivity of rye," Food Microbiology, vol. 24, no. 2, pp. 175-186, 2007.

[14] K. Katina, K.-H. Liukkonen, A. Kaukovirta-Norja et al., "Fermentation-induced changes in the nutritional value of native or germinated rye," Journal of Cereal Science, vol. 46, no. 3, pp. 348-355, 2007.

[15] T. Bhanja Dey and R. C. Kuhad, "Upgrading the antioxidant potential of cereals by their fungal fermentation under solidstate cultivation conditions," Letters in Applied Microbiology, vol. 59, no. 5, pp. 493-499, 2014.

[16] I.-C. Sheih, T. J. Fang, T.-K. Wu, C.-H. Chang, and R.-Y. Chen, "Purification and properties of a novel phenolic antioxidant from Radix astragali fermented by Aspergillus oryzae M29," Journal of Agricultural and Food Chemistry, vol. 59, no. 12, pp. 6520-6525, 2011.

[17] I.-H. Lee, Y.-H. Hung, and C.-C. Chou, "Solid-state fermentation with fungi to enhance the antioxidative activity, total phenolic and anthocyanin contents of black bean," International Journal of Food Microbiology, vol. 121, no. 2, pp. 150-156, 2008.

[18] E.-S. M. Abdel-Aal, T.-M. Choo, S. Dhillon, and I. Rabalski, "Free and bound phenolic acids and total phenolics in black, blue, and yellow barley and their contribution to free radical scavenging capacity," Cereal Chemistry Journal, vol. 89, no. 4, pp. 198-204, 2012.

[19] S. Chandra, S. Khan, B. Avula et al., "Assessment of total phenolic and flavonoid content, antioxidant properties, and yield of aeroponically and conventionally grown leafy vegetables and fruit crops: a comparative study," Evidence-Based Complementary and Alternative Medicine, vol. 2014, pp. 1-9, Article ID 253875, 2014.

[20] J. Zhishen, T. Mengcheng, and W. Jianming, "The determination of flavonoid contents in mulberry and their scavenging effects on superoxide radicals," Food Chemistry, vol. 64, no. 4, pp. 555-559, 1999.

[21] I. F. F. Benzie and J. J. Strain, "The ferric reducing ability of plasma (FRAP) as a measure of "antioxidant power": the FRAP assay," Analytical Biochemistry, vol. 239, no. 1, pp. 70-76, 1996.

[22] S. Lin, Q. Zhu, L. Wen et al., "Production of quercetin, kaempferol and their glycosidic derivatives from the aqueousorganic extracted residue of litchi pericarp with Aspergillus awamori," Food Chemistry, vol. 145, pp. 220-227, 2014.

[23] S. Kariluoto, M. Aittamaa, M. Korhola, H. Salovaara, L. Vahteristo, and V. Piironen, "Effects of yeasts and bacteria on the levels of folates in rye sourdoughs," International Journal of Food Microbiology, vol. 106, no. 2, pp. 137-143, 2006. 
[24] Y.-C. Lin and C.-C. Chou, "Effect of heat treatment on total phenolic and anthocyanin contents as well as antioxidant activity of the extract from Aspergillus awamori-fermented black soybeans, a healthy food ingredient," International Journal of Food Sciences and Nutrition, vol. 60, no. 7, pp. 627-636, 2009.

[25] C. M. Oliveira, A. C. S. Ferreira, V. De Freitas, and A. M. S. Silva, "Oxidation mechanisms occurring in wines," Food Research International, vol. 44, no. 5, pp. 1115-1126, 2011.

[26] T. Beta, L. W. Rooney, L. T. Marovatsanga, and J. R. N. Taylor, "Effect of chemical treatments on polyphenols and malt quality in sorghum," Journal of Cereal Science, vol. 31, no. 3, pp. 295-302, 2000.

[27] F. V. Dulf, D. C. Vodnar, E.-H. Dulf, Z. Diaconeasa, and C. Socaciu, "Liberation and recovery of phenolic antioxidants and lipids in chokeberry (Aronia melanocarpa) pomace by solid-state bioprocessing using Aspergillus Niger and Rhizopus oligosporus strains," LWT-Food Science and Technology, vol. 87, pp. 241-249, 2018.

[28] C. Zambrano, A. Kotogán, O. Bencsik et al., "Mobilization of phenolic antioxidants from grape, apple and pitahaya residues via solid state fungal fermentation and carbohydrase treatment," LWT-Food Science and Technology, vol. 89, pp. 457-465, 2018.

[29] M. Z. Guang, Y. Y. Hong, L. H. Hong et al., "Laccase activities of a soil fungus Penicillium simplicissimum in relation to lignin degradation," World Journal of Microbiology and Biotechnology, vol. 22, no. 4, pp. 317-324, 2006. 